\title{
An All-Digital On-Chip Silicon Oscillator with Automatic VT Range Selection Relative Modeling
}

\author{
Ching-Che Chung, Member IEEE, and Jhih-Wei Li \\ Department of Computer Science and Information Engineering \\ National Chung Cheng University \\ No. 168, University Rd., Min-Hsiung, Chia-Yi, Taiwan \\ Email:wildwolf@cs.ccu.edu.tw
}

\begin{abstract}
In this paper, a $5 \mathrm{MHz}$ all-digital on-chip silicon oscillator is presented. The proposed on-chip oscillator uses a voltage and temperature classifier with the proposed linear calculator to compensate for voltage and temperature variations at chip run time. The maximum frequency errors with temperature and voltage variations are $0.21 \%$ and $0.97 \%$, respectively. A systematic way to choose the standard cells for building the proposed design is also discussed in this paper.
\end{abstract}

\section{INTRODUCTION}

In wireless sensor networks and biomedical devices, these systems operate with batteries and are highly integrated. Timing references are essential parts of these systems. In recent years, many researches had been devoted to develop CMOS-compatible on-chip oscillators [1]-[9] for replacing off-chip quartz crystal oscillators. The natural resonant frequency corresponding to the absolute value of $\mathrm{RC}$ or LC is commonly adopted for the oscillator design [3]. However, this oscillator requires canceling the temperature dependency of the passive components, and thus, the accuracy of the output frequency strongly depends on the process variations. A mobility-based frequency reference [1] and thermaldiffusivity-based frequency reference [2] have relatively small process variations, but their approaches have strong temperature dependency. Thus, they need accurate temperature sensors to compensate for the output frequency with temperature variations, and their approaches occupy a large chip area. In addition, the voltage variations are not considered in these approaches [1]-[3].

A frequency-locked-loop-based reference generator [4] uses a bias current circuit with a frequency-to-current converter to overcome temperature and voltage variations. However, the output frequency still depends on the variations of the resistance and the capacitance. Relaxation oscillators [5],[7] with power averaging feedback can tolerate both temperature and voltage variations. However, the resistive divider for the voltage reference require cancelling of temperature dependency, and a small voltage variations on the reference voltage (i.e. $2 \mathrm{mV}$ ) can cause $0.4 \%$ frequency error [5], and thus, they are sensitive to the supply noise. Relaxation oscillator [6] requires a bias generator to overcome voltage

This work was supported in part by the National Science Council of Taiwan, under Grant NSC101-2221-E-194-063. and temperature variations. However, the bias generator occupies a large chip area.

An all-digital on-chip oscillator with the relative reference modeling is proposed in [9]. The digital approach makes it easy to design the on-chip oscillator. However, a high order polynomial is required to minimize the modeling error, and thus, a mapper is required to reduce the area cost. In this paper, the proposed design also uses the relative modeling to build up the on-chip oscillator. However, a voltage and temperature classifier is proposed to reduce the modeling error of [9] to achieve a better accuracy of the output frequency. The proposed design can operate with a low supply voltage and very suitable for low-power and low-cost system-on-a-chip (SoC) application.

\section{RELATIVE REFERENCE MODELING}

The propagation delay time of the logic cells are easily affected by process, voltage, and temperature (PVT) variations. If we choose any three logic cells from the standard cell library, and one of them uses as a reference delay cell (RDC), and the other cells use as the compare delay cell 1 (CDC1) and the compared delay cell 2 (CD2). The delay ratio between these logic cells can be expressed as

$$
\begin{array}{r}
R 1(P, V, T)=\frac{D R D C(P, V, T)}{\operatorname{DCDC1}(P, V, T)} \\
R 2(P, V, T)=\frac{D R D C(P, V, T)}{D \operatorname{CDC} 2(P, V, T)}
\end{array}
$$

where $\mathrm{D}_{\mathrm{RDC}}(\mathrm{P}, \mathrm{V}, \mathrm{T}), \mathrm{D}_{\mathrm{CDC} 1}(\mathrm{P}, \mathrm{V}, \mathrm{T})$, and $\mathrm{D}_{\mathrm{CDC} 2}(\mathrm{P}, \mathrm{V}, \mathrm{T})$ are the delay time of the RDC, $\mathrm{CDC} 1$, and $\mathrm{CDC} 2$, respectively.

For a fixed supply voltage $(\mathrm{V})$ and certain process corner $(\mathrm{P}), \mathrm{D}_{\mathrm{RDC}}(\mathrm{P}, \mathrm{V}, \mathrm{T})$ and $\mathrm{D}_{\mathrm{CDCl}}(\mathrm{P}, \mathrm{V}, \mathrm{T})$ are both increased and decreased with temperature variations. Thus, the range of $\mathrm{R} 1(\mathrm{P}, \mathrm{V}, \mathrm{T})$ means the temperature coefficients difference between RDC and CDC1. Therefore, if there exists a RDC and $\mathrm{CDC} 1$ pair, which the range of the $\mathrm{R} 1(\mathrm{P}, \mathrm{V}, \mathrm{T})$ at all process corners with different voltages are not overlapped. Then, $\mathrm{R} 1(\mathrm{P}, \mathrm{V}, \mathrm{T})$ can be used to roughly determine the supply voltage of the chip. Similarly, for a fixed temperature (T) and 
certain process corner $(\mathrm{P}), \mathrm{D}_{\mathrm{RDC}}(\mathrm{P}, \mathrm{V}, \mathrm{T})$ and $\mathrm{D}_{\mathrm{CDC} 2}(\mathrm{P}, \mathrm{V}, \mathrm{T})$ are both increased and decreased with voltage variations. Thus, if there exists a RDC and $\mathrm{CDC} 2$ pair, which the range of the $\mathrm{R} 2(\mathrm{P}, \mathrm{V}, \mathrm{T})$ at all process corners with different temperatures are not overlapped. Then, $\mathrm{R} 2(\mathrm{P}, \mathrm{V}, \mathrm{T})$ can be used to roughly determine the temperature of the chip. In this paper, the $\mathrm{R} 1(\mathrm{P}, \mathrm{V}, \mathrm{T})$ and $\mathrm{R} 2(\mathrm{P}, \mathrm{V}, \mathrm{T})$ are used by the proposed voltage and temperature classifier, and the accuracy of the output frequency of the on-chip ring oscillator can be significantly improved.

\section{SYSTEM ARCHITECTURE}

\section{A. Delay Ratio Estimator}

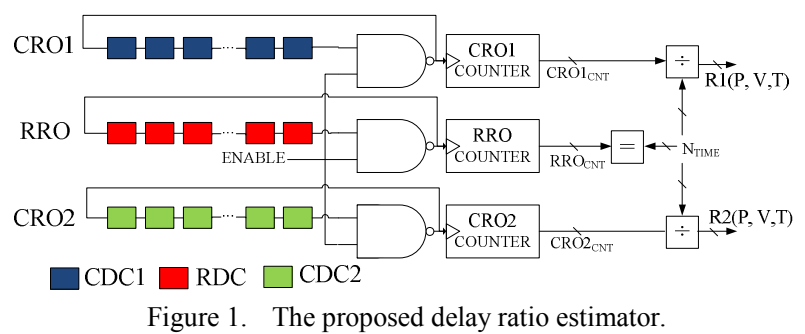

The block diagram of the proposed delay ratio estimator (DRE) is shown in Fig. 1. In DRE, three logic cells, RDC, $\mathrm{CDC} 1, \mathrm{CDC} 2$ are used to create three ring oscillators, the reference ring oscillator (RRO), the compared ring oscillator 1 (CRO1), and the compared ring oscillator 2 (CRO2), respectively. The output of the ring oscillator is connected to the counter to record the oscillation cycles of the oscillator. The value of these counters can be used to calculate the delay ratio $\mathrm{R} 1(\mathrm{P}, \mathrm{V}, \mathrm{T})$ and $\mathrm{R} 2(\mathrm{P}, \mathrm{V}, \mathrm{T})$ as follows:

$$
\begin{aligned}
& R 1(P, V, T)=\frac{C R O 1_{C N T}}{R_{C O N T}} \\
& R 2(P, V, T)=\frac{C R O 2_{C N T}}{R_{C O N T}}
\end{aligned}
$$

where $\mathrm{CRO}_{\mathrm{CNT}}, \mathrm{CRO} 2_{\mathrm{CNT}}$ and $\mathrm{RRO}_{\mathrm{CNT}}$ are the output of the CRO1 counter, the CRO2 counter, and the RRO counter, respectively. The RRO counter will count from 0 to $\mathrm{N}_{\text {TIME}}$, and then the three ring oscillators are stopped. The value of $\mathrm{N}_{\text {TIME }}$ is set to 2047 , thus the delay ratio $\mathrm{R} 1(\mathrm{P}, \mathrm{V}, \mathrm{T})$ and $\mathrm{R} 2(\mathrm{P}, \mathrm{V}, \mathrm{T})$ can be computed without divider circuits.

\section{B. Digitally Controlled Oscillator}

The proposed DCO architecture is shown in Fig. 2. The output of the RRO triggers the DCO counter, and when the output value of the DCO counter equals to the input control code (DCO_CODE), a pulse is generated, and then the DCO counter is reset. To generate the output clock with a $50 \%$ duty cycle, a divided-by- 2 circuit is added before output. The output frequency of the DCO can be expressed as follows:

$$
F D C O=\frac{1}{P R R O(P, V, T) \times D C O \_C O D E \times 2}
$$

where $\mathrm{P}_{\mathrm{RRO}}(\mathrm{P}, \mathrm{V}, \mathrm{T})$ is the period of the RRO, and $\mathrm{F}_{\mathrm{DCO}}$ is the output frequency of the DCO. The period of RRO is easily affected by PVT variations, thus the input control code (DCO_CODE) can be used to adjust the output frequency with PVT variations.

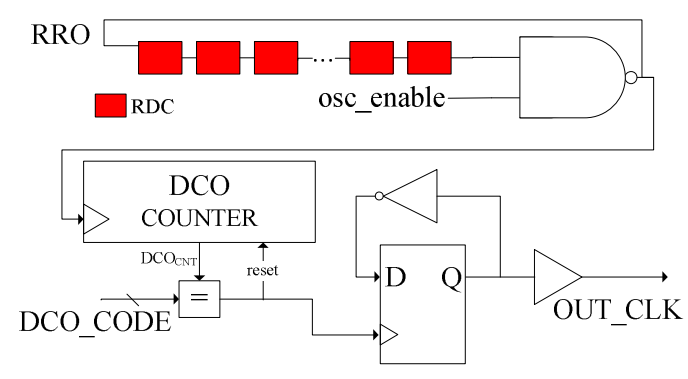

Figure 2. The proposed DCO architecture.

C. Cell Selection Rules for Delay Ratio Estimator

Choose three cells from the cell library to build up the delay ratio estimator (DRE) (RDC, CDC1, CDC2)

Perform SPICE simulation of DRE with PVT variations to obtain R1(P, V, T), R2(P, V, T), G $\mathrm{R}_{\mathrm{R} 1}, \mathrm{~S}_{\mathrm{R} 1}, \mathrm{G}_{\mathrm{R} 2}$ and $\mathrm{S}_{\mathrm{R} 2}$

Choose best cell combination for RDC, $\mathrm{CDC} 1$ and $\mathrm{CDC} 2$ based on $\mathrm{G}_{\mathrm{R} 1}, \mathrm{~S}_{\mathrm{R} 1}, \mathrm{G}_{\mathrm{R} 2}$ and $\mathrm{S}_{\mathrm{R} 2}$

Figure 3. Flow chart of how to choose cells from the cell library.

Fig. 3 shows the cell selection flow chart for RDC, CDC1, and CDC2. At first, any three logic cells are selected from the standard cell library to build up the delay ratio estimator. Subsequently, we need to perform SPICE simulation of the DRE with PVT variations to obtain delay ratios, R1 $(\mathrm{P}, \mathrm{V}, \mathrm{T})$ and $\mathrm{R} 2(\mathrm{P}, \mathrm{V}, \mathrm{T})$. In this paper, the voltage varies from $\mathrm{V}_{1}$ to $\mathrm{V}_{5}$ $\left(\mathrm{V}_{1}=0.90 \mathrm{~V}, \mathrm{~V}_{2}=0.95 \mathrm{~V}, \mathrm{~V}_{3}=1.00 \mathrm{~V}, \mathrm{~V}_{4}=1.05 \mathrm{~V}\right.$, and $\left.\mathrm{V}_{5}=1.10 \mathrm{~V}\right)$, and temperature varies from $\mathrm{T}_{1}$ to $\mathrm{T}_{4},\left(\mathrm{~T}_{1}=0^{\circ} \mathrm{C}, \mathrm{T}_{2}=25^{\circ} \mathrm{C}\right.$, $\mathrm{T}_{3}=50^{\circ} \mathrm{C}$, and $\mathrm{T}_{4}=75^{\circ} \mathrm{C}$ ). In addition, the process variation includes typical process corner (TT), best process corner (FF), and worst process corner (SS). Therefore, it needs to simulate the DRE in totally $60=(3 \times 5 \times 4)$ different $\mathrm{P}, \mathrm{V}, \mathrm{T}$ combinations.

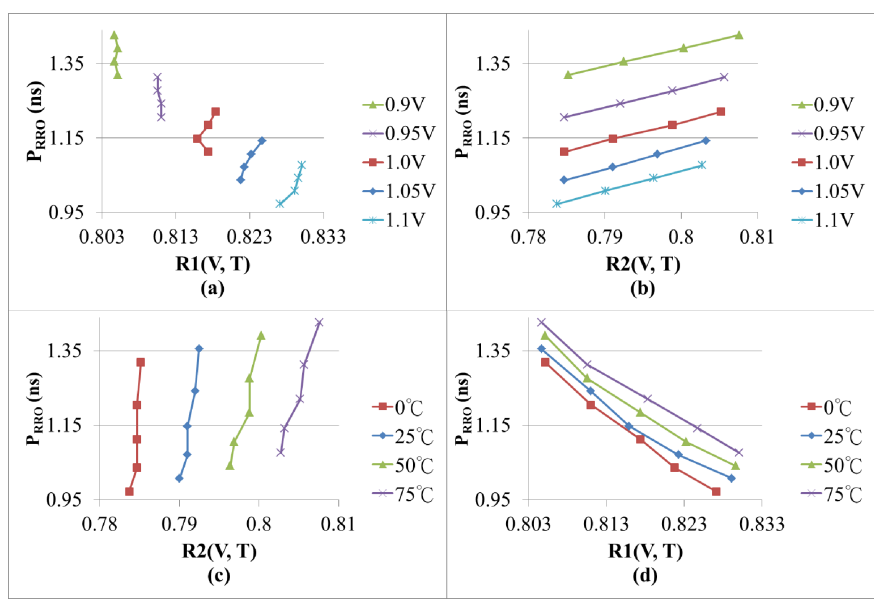

Figure 4. Delay ratios $\mathrm{R} 1(\mathrm{~V}, \mathrm{~T})$ and $\mathrm{R} 2(\mathrm{~V}, \mathrm{~T})$ versus $\mathrm{P}_{\mathrm{RRO}}(\mathrm{V}, \mathrm{T})$ in typical process corner.

Fig. 4 shows the delay ratios $\mathrm{R} 1(\mathrm{~V}, \mathrm{~T})$ and $\mathrm{R} 2(\mathrm{~V}, \mathrm{~T})$ versus the period of the RRO, $\mathrm{P}_{\mathrm{RRO}}(\mathrm{V}, \mathrm{T})$ in typical process corner. In Fig. 4(a), with a fixed voltage value, the delay ratio $\mathrm{R} 1$ varies 
with temperature variations. $\Delta \mathrm{TT}_{\mathrm{R} 1 \mathrm{n}}$ of Eq. 6 means the spacing between the R1 delay ratio curves with voltage $V_{n}$ and voltage $\mathrm{V}_{\mathrm{n}+1}$ in typical process corner. In Fig. 4(c), with a fixed temperature value, the delay ratio $\mathrm{R} 2$ varies with voltage variations. $\Delta \mathrm{TT}_{\mathrm{R} 2 \mathrm{j}}$ of Eq. 7 means the spacing between the $\mathrm{R} 2$ delay ratio curves with temperature $T_{j}$ and temperature $T_{j+1}$ in typical process corner. The values of $\Delta \mathrm{TT}_{\mathrm{R} 1 \mathrm{n}}$ and $\Delta \mathrm{TT}_{\mathrm{R} 2 \mathrm{j}}$ should be greater than zero, so that the delay ratios $\mathrm{R} 1(\mathrm{~V}, \mathrm{~T})$ and $\mathrm{R} 2(\mathrm{~V}, \mathrm{~T})$ can be used to roughly estimate the supply voltage and operation temperature at chip run time. Therefore, if the DRE fails to meet this requirement, the current cell combinations are dropped, and then, we need to choose other cell combinations and repeat the SPICE simulation of the DRE again.

$$
\begin{gathered}
\Delta T_{R 1 n}=\operatorname{MIN}\left(R 1\left(T T, V_{n}+1, T\right)\right)-\operatorname{MAX}\left(R 1\left(T T, V_{n}, T\right)\right) \\
\Delta T_{R 2 j}=\operatorname{MIN}\left(R 2\left(T T, V, T_{j}+1\right)\right)-\operatorname{MAX}\left(R 2\left(T T, V, T_{j}\right)\right) \\
\Delta T T_{R 1}=\sum_{n=1}^{4} \Delta T T_{R 1} n \\
\Delta T T_{R 2}=\sum_{j=1}^{3} \Delta T T_{R 2} j \\
G_{R 1}=\left(\Delta T T_{R 1}+\Delta S S_{R 1}+\Delta F F_{R 1}\right) \\
G_{R 2}=\left(\Delta T T_{R 2}+\Delta S S_{R 2}+\Delta F F_{R 2}\right) \\
S_{R 1}=\operatorname{Std}\left(\Delta T T_{R 1}, \Delta S S_{R 1}, \Delta F F_{R 1}\right) \\
S_{R 2}=\operatorname{Std}\left(\Delta T T_{R 2}, \Delta S S_{R 2}, \Delta F F_{R 2}\right)
\end{gathered}
$$

The DRE should be simulated with different process corners. In Eq. 10, $\mathrm{G}_{\mathrm{R} 1}$ of the current DRE is defined as the summation of $\Delta \mathrm{TT}_{\mathrm{R} 1}, \Delta \mathrm{SS}_{\mathrm{R} 1}$, and $\Delta \mathrm{FF}_{\mathrm{R} 1}$, where $\Delta \mathrm{TT}_{\mathrm{R} 1}, \Delta \mathrm{SS}_{\mathrm{R} 1}$, and $\Delta F_{\mathrm{R} 1}$ are the summation of the $\mathrm{R} 1$ curve spacing in typical process corner, worst process corner, and best process corner, respectively. Similarly, $G_{R 2}$ of the current DRE is defined as the summation of $\Delta \mathrm{TT}_{\mathrm{R} 2}, \Delta \mathrm{SS}_{\mathrm{R} 2}$, and $\Delta \mathrm{FF}_{\mathrm{R} 2}$, where $\Delta \mathrm{TT}_{\mathrm{R} 2}, \Delta \mathrm{SS}_{\mathrm{R} 2}$, and $\Delta \mathrm{FF}_{\mathrm{R} 2}$ are the summation of the $\mathrm{R} 2$ curve spacing in typical process corner, worst process corner, and best process corner, respectively. In Eq. $12, \mathrm{~S}_{\mathrm{R} 1}$ is the standard deviation of $\Delta \mathrm{TT}_{\mathrm{R} 1}, \Delta \mathrm{SS}_{\mathrm{R} 1}$, and $\Delta \mathrm{FF}_{\mathrm{R} 1}$, and $\mathrm{S}_{\mathrm{R} 2}$ is the standard deviation of $\Delta \mathrm{TT}_{\mathrm{R} 2}, \Delta \mathrm{SS}_{\mathrm{R} 2}$, and $\Delta \mathrm{FF}_{\mathrm{R} 2}$. We need to compute $\mathrm{G}_{\mathrm{R} 1}, \mathrm{G}_{\mathrm{R} 2}, \mathrm{~S}_{\mathrm{R} 1}$, and $\mathrm{S}_{\mathrm{R} 2}$ of all possible cell combinations, and the cell combination with largest values of $G_{R 1}$ and $G_{R 2}$, and smallest values of $\mathrm{S}_{\mathrm{R} 1}, \mathrm{~S}_{\mathrm{R} 2}$ is the best choice for design the DRE. However, if we cannot find this best choice, the cell combination with a larger $G_{R 1}$ value and smaller $S_{R 1}$ value is a better choice. In this paper, we use a $90 \mathrm{~nm}$ cell library to implement the DRE, and the best cell combination is (AND3X1, NAND4XL, DLY1X1) for (RDC, CDC1, CDC2).

\section{On-Chip Oscillator with Relative Modeling}

The proposed on-chip ring oscillator architecture which uses the relative reference modeling is shown in Fig. 5. It is composed of a delay ratio estimator, a voltage classifier, a temperature classifier, a linear calculator, and a digitally controlled oscillator (DCO). The DRE estimates the R1(V,T) and the $\mathrm{R} 2(\mathrm{~V}, \mathrm{~T})$ at chip run time under voltage and temperature variations. In this paper, we need to measure the values of $\mathrm{R} 1(\mathrm{~V}, \mathrm{~T}), \mathrm{R} 2(\mathrm{~V}, \mathrm{~T})$, and $\mathrm{P}_{\mathrm{RRO}}(\mathrm{V}, \mathrm{T})$ with five different voltages $\left(V_{1}\right.$ to $\left.V_{5}\right)$ and four different temperatures $\left(T_{1}\right.$ to $\left.T_{4}\right)$,
Therefore, it needs to measure the values of $\mathrm{R} 1(\mathrm{~V}, \mathrm{~T}), \mathrm{R} 2(\mathrm{~V}, \mathrm{~T})$, and $\mathrm{P}_{\mathrm{RRO}}(\mathrm{V}, \mathrm{T})$ in totally 20 different $(\mathrm{V}, \mathrm{T})$ cases.

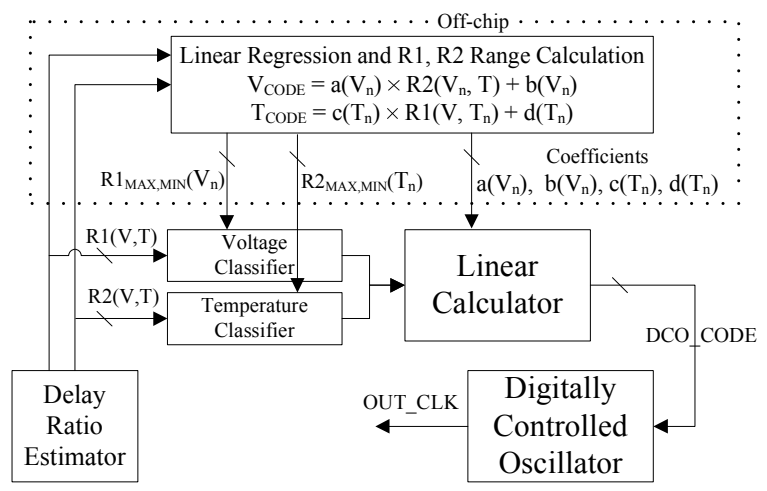

Figure 5. The proposed on-chip oscillator architecture.

The maximum value and minimum value of $\mathrm{R} 1\left(\mathrm{~V}_{\mathrm{n}}, \mathrm{T}\right)$ at voltage $V_{n}$ with temperature variations $\left(T_{1}\right.$ to $\left.T_{4}\right)$ will be found in the off-chip process, and are stored as $\mathrm{R} 1_{\mathrm{MAX}}\left(\mathrm{V}_{\mathrm{n}}\right)$ and $R 1_{\text {MIN }}\left(V_{n}\right)$, where $V_{n}$ is $V_{1}$ to $V_{5}$. Similarly, the maximum value and minimum value of $R 2\left(V, T_{n}\right)$ at temperature $T_{n}$ with voltage variations $\left(V_{1}\right.$ to $\left.V_{5}\right)$ will be found in the off-chip process, and are stored as $R 2_{\text {MAX }}\left(T_{n}\right)$ and $R 2_{\text {MIN }}\left(T_{n}\right)$, where $T_{n}$ is $\mathrm{T}_{1}$ to $\mathrm{T}_{4}$. In the off-chip process, we perform the linear regression on the $R 2\left(V_{n}, T\right)$ versus DCO_CODE at voltage $V_{n}$ to obtain the coefficients $a\left(V_{n}\right)$ and $b\left(V_{n}\right)$, where $V_{n}$ is $V_{1}$ to $\mathrm{V}_{5}$. In addition, we also perform the linear regression on the $\mathrm{R} 1\left(\mathrm{~V}, \mathrm{~T}_{\mathrm{n}}\right)$ versus DCO_CODE at temperature $\mathrm{T}_{\mathrm{n}}$ to obtain the coefficients $c\left(T_{n}\right)$ and $\bar{d}\left(T_{n}\right)$, where $T_{n}$ is $T_{1}$ to $T_{4}$. Thus there are totally 18 coefficients stored in the linear calculator for further voltage and temperature compensation at chip run time.

When the values of $R 1_{\text {MAX }}\left(V_{n}\right), R 1_{\text {MIN }}\left(V_{n}\right), R 2_{\text {MAX }}\left(T_{n}\right)$, and $R 2_{\mathrm{MIN}}\left(\mathrm{T}_{\mathrm{n}}\right), \mathrm{a}\left(\mathrm{V}_{\mathrm{n}}\right), \mathrm{b}\left(\mathrm{V}_{\mathrm{n}}\right), \mathrm{c}\left(\mathrm{T}_{\mathrm{n}}\right)$, and $\mathrm{d}\left(\mathrm{T}_{\mathrm{n}}\right)$ for $\mathrm{V}_{1}$ to $\mathrm{V}_{5}$ and $\mathrm{T}_{1}$ to $\mathrm{T}_{4}$ are determined in the off-chip process, the proposed on-chip oscillator are now ready for generating the required target frequency $\left(\mathrm{F}_{\mathrm{DCO}}\right)$. At chip run time, the DRE estimates $\mathrm{R} 1(\mathrm{~V}, \mathrm{~T})$ and $\mathrm{R} 2(\mathrm{~V}, \mathrm{~T})$ with a unknown supply voltage $(\mathrm{V})$ and a unknown operation temperature $(\mathrm{T})$. The voltage classifier uses the $R 1_{\text {MAX }}\left(V_{n}\right)$ and $R 1_{\text {MIN }}\left(V_{n}\right)$ to roughly estimate the unknown supply voltage. For example, if $\mathrm{R} 1(\mathrm{~V}, \mathrm{~T})$ is smaller than $\mathrm{R} 1_{\mathrm{MAX}}\left(\mathrm{V}_{2}\right)$ but is larger than $\mathrm{R} 1_{\mathrm{MIN}}\left(\mathrm{V}_{2}\right)$, and then, the current supply voltage can be estimated as $V_{2}$. The temperature classifier uses the $\mathrm{R} 2_{\mathrm{MAX}}\left(\mathrm{T}_{\mathrm{n}}\right)$ and $\mathrm{R} 2_{\mathrm{MIN}}\left(\mathrm{T}_{\mathrm{n}}\right)$ to roughly estimate the unknown operation temperature. For example, if $\mathrm{R} 2(\mathrm{~V}, \mathrm{~T})$ is smaller than $\mathrm{R} 2_{\mathrm{MAX}}\left(\mathrm{T}_{3}\right)$ but is larger than $\mathrm{R} 2_{\mathrm{MIN}}\left(\mathrm{T}_{3}\right)$, and then, the current operation temperature can be estimated as $\mathrm{T}_{3}$. Then, the linear calculator uses Eq. 14 and Eq. 15 to calculate two DCO control codes $\left(\mathrm{V}_{\mathrm{CODE}}\right.$ and $\left.\mathrm{T}_{\mathrm{CODE}}\right)$. Finally, the DCO control code for the $\mathrm{DCO}$ is the average of the $\mathrm{V}_{\mathrm{CODE}}$ and $\mathrm{T}_{\mathrm{CODE}}$. (i.e. $\mathrm{DCO}$ CODE $=\left(\mathrm{V}_{\mathrm{CODE}}+\right.$ $\left.\mathrm{T}_{\text {CODE }}\right) / 2$ ).

$$
\begin{aligned}
& \mathrm{V} \text { CODE }=\mathrm{a}\left(\mathrm{V}_{\mathrm{n}}\right) \times \mathrm{R} 2\left(\mathrm{~V}_{\mathrm{n}}, \mathrm{T}\right)+\mathrm{b}\left(\mathrm{V}_{\mathrm{n}}\right) \\
& \mathrm{T} \text { CODE }=\mathrm{c}\left(\mathrm{T}_{\mathrm{n}}\right) \times \mathrm{R} 1\left(\mathrm{~V}, \mathrm{~T}_{\mathrm{n}}\right)+\mathrm{d}\left(\mathrm{T}_{\mathrm{n}}\right)
\end{aligned}
$$

In some special cases, for example, if $\mathrm{R} 1(\mathrm{~V}, \mathrm{~T})$ is smaller than $\mathrm{R} 1_{\mathrm{MIN}}\left(\mathrm{V}_{3}\right)$ but is larger than $\mathrm{R} 1_{\mathrm{MAX}}\left(\mathrm{V}_{2}\right)$, the voltage classifier can only determine the unknown supply voltage is between $\mathrm{V}_{2}$ and $\mathrm{V}_{3}$. In this case, the $\mathrm{V}_{\mathrm{CODE}}$ can be computed 
by $\left[a\left(V_{2}\right)+a\left(V_{3}\right)\right] / 2 \times R 2(V, T)+\left[b\left(V_{2}\right)+b\left(V_{3}\right)\right] / 2$. Similarly, if the temperature classifier determines the unknown operation temperature is between $\mathrm{T}_{2}$ and $\mathrm{T}_{3}$, the $\mathrm{T}_{\mathrm{CODE}}$ can be computed by $\left[\mathrm{c}\left(\mathrm{T}_{2}\right)+\mathrm{c}\left(\mathrm{T}_{3}\right)\right] / 2 \times \mathrm{R} 1(\mathrm{~V}, \mathrm{~T})+\left[\mathrm{d}\left(\mathrm{T}_{2}\right)+\mathrm{d}\left(\mathrm{T}_{3}\right)\right] / 2$.

\section{EXPERIMENTAL RESULTS}

The proposed on-chip oscillator circuit is implemented in a standard $90 \mathrm{~nm} 1 \mathrm{P} 9 \mathrm{M}$ CMOS process. The operating voltage ranges from $0.90 \mathrm{~V}$ to $1.10 \mathrm{~V}$, and temperature range is from $0^{\circ} \mathrm{C}$ to $75^{\circ} \mathrm{C}$. The layout of the test chip is shown in Fig. 6 . The active area is $180 \mu \mathrm{m} \times 180 \mu \mathrm{m}$, and chip area including I/O pads is $830 \mu \mathrm{m} \times 830 \mu \mathrm{m}$.

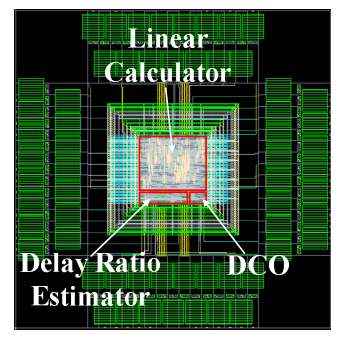

Figure 6. Layout of the test chip.

Fig. 7 shows the output frequency of the proposed on-chip oscillator with PVT variations. The target frequency is $5 \mathrm{MHz}$. Table I shows the comparisons with the state-of-the-art designs. The frequency error of the proposed on-chip oscillator with temperature variations is $0.21 \%$ in typical process corner, which is smaller than prior researches. Although [2] has a smaller temperature variations, it does not tolerate the voltage variations. The maximum frequency error of the proposed design with voltage variations is $0.97 \%$ in typical process corner. Relaxation oscillators [5],[7] can achieve relatively small voltage variations. However, a small voltage variations on the reference voltage (i.e. $2 \mathrm{mV}$ ) can cause $0.4 \%$ frequency error [5], and thus, they are sensitive to the supply noise. The maximum output frequency error with PVT variations ranges from $-2.83 \%$ to $+2.49 \%$.
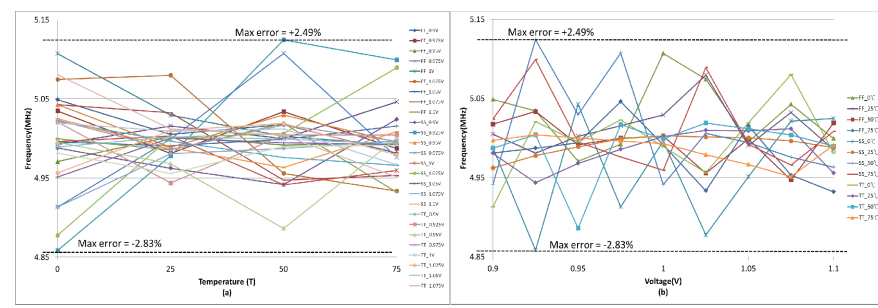

\section{CONCLUSION}

The proposed on-chip oscillator with a relative modeling uses the voltage and temperature classifier to roughly estimate the supply voltage and operation temperature at chip run time. Therefore, the frequency error can be significant reduced by a linear equation-based compensation approach. The proposed design can be implemented by standard cells, and we also propose the cell selection rules to choose the cells for the delay ratio estimator. As a result, the proposed design provides a systematic way to automatically generate the on-chip oscillator with PVT variations tolerance. Thus the proposed design can operate with a low supply voltage, and is very suitable for low-power and low-cost system-on-a-chip application.

\section{REFERENCES}

[1] Fabio Sebastiano, et al., "A 65-nm CMOS temperature-compensated mobility-based frequency reference for wireless sensor networks," IEEE Journal of Solid-State Circuits, vol. 46, no. 7, pp. 1544-1552, Jul. 2011.

[2] S. Mahdi Kashmiri, Kamran Souri, and Kofi A. A. Makinwa, "A scaled thermal-diffusivity-based $16 \mathrm{MHz}$ frequency reference in $0.16 \mu \mathrm{m}$ CMOS," IEEE Journal of Solid-State Circuits, vol. 47, no. 7, pp. 1535 1545, Jul. 2012.

[3] Valentijn De Smedt, et al., “A 66uW 86ppm $/{ }^{\circ} \mathrm{C}$ fully-integrated $6 \mathrm{MHz}$ Wienbridge oscillator with a $172 \mathrm{~dB}$ phase noise FOM," IEEE Journal of Solid-State Circuits, vol. 44, no. 7, pp. 1990-2001, Jul. 2009.

[4] Ken Ueno, Tetsuya Asai, and Yoshihito Amemiya, "A 30-MHz 90$\mathrm{ppm} /{ }^{\circ} \mathrm{C}$ fully-integrated clock reference generator with frequencylocked loop," in Proceedings of European Solid-State Circuits Conf. (ESSCIRC), Sep. 2009, pp. 392-395.

[5] Yusuke Tokunaga, et al., "An on-chip CMOS relaxation oscillator with voltage averaging feedback," IEEE Journal of Solid-State Circuits, vol. 45, no. 6, pp. 1150-1158, Jun. 2010.

[6] Takashi Tokairin, et al., "A $280 \mathrm{nW}, 100 \mathrm{kHz}, 1$-cycle start-up time, onchip CMOS relaxation oscillator employing a feedforward period control scheme," in Digest of Technical Papers, Symposium on VLSI Circuits, Jun. 2012, pp. 16-17.

[7] Yusuke Tokunaga, Shiro Sakiyama, and Shiro Dosho, "An over 20,000 quality factor on-chip relaxation oscillator using power averaging feedback with a chopped amplifier," in Digest of Technical Papers, Symposium on VLSI Circuits, Jun. 2010, pp. 111-112.

[8] Guseong-dong, Yuseong-gu, Daejon and Republic, "A $10 \mathrm{MHz} 80 \mu \mathrm{W}$ $67 \mathrm{ppm} /{ }^{\circ} \mathrm{C} \mathrm{CMOS}$ reference clock oscillator with a temperature compensated feedback loop in $0.18 \mu \mathrm{m}$ CMOS," in Digest of Technical Papers, Symposium on VLSI Circuits, Jun. 2009, pp. 226-227.

[9] Chien-Ying Yu, Jui-Yuan Yu, and Chen-Yi Lee, "A Low Voltage AllDigital On-Chip Oscillator Using Relative Reference Modeling," IEEE Transactions on Very Large Scale Integration (VLSI) Systems, vol. 20, no. 9 , pp. 1615-1620, Sep. 2012.

Figure 7. Output frequency with PVT variations (a) $\mathrm{x}$-axis is tempereature (b) $\mathrm{x}$-axis is voltage.

TABLE I

\begin{tabular}{|c|c|c|c|c|c|c|c|c|c|}
\hline & This work & [1]JSSC'11 & [2]JSSC'12 & [3]JSSC'09 & [4]ESSCIRC'09 & [5]JSSC'10 & [7]VLSIC'10 & [8]VLSIC'09 & [9]TVLSI'12 \\
\hline Technology(nm) & 90 & 65 & 160 & 65 & 350 & 180 & 65 & 180 & 90 \\
\hline Frequency $(\mathrm{MHz})$ & 5 & 0.15 & 16 & 6 & 30 & 14 & 6 & 10 & 5 \\
\hline Temp. Range & $0 \sim 75$ & $-55 \sim 125$ & $-55 \sim 125$ & $0 \sim 120$ & $-20 \sim 100$ & $-40 \sim 125$ & $-40 \sim 125$ & $-20 \sim 100$ & $0 \sim 75$ \\
\hline Vari. with Temp. & $0.21 \%$ & $0.5 \%$ & $0.1 \%$ & $0.6 \%$ & $0.7 \%$ & $0.75 \%$ & $0.20 \%$ & $0.4 \%$ & $1 \%$ \\
\hline VDD Range & $0.9 \sim 1.1$ & fixed $1.2 \mathrm{v}$ & fixed $1.8 \mathrm{v}$ & fixed $1.2 \mathrm{v}$ & fixed $1.8 \mathrm{v}$ & $1.7 \sim 1.9$ & $1.15 \sim 1.35$ & $1.2 \sim 3.0$ & $0.9 \sim 1.1$ \\
\hline Vari. with VDD & $0.97 \%$ & $\mathrm{~N} / \mathrm{A}$ & N/A & N/A & $\mathrm{N} / \mathrm{A}$ & $0.16 \%$ & $0.26 \%$ & $0.05 \%$ & $1 \%$ \\
\hline power(mW) & 1.42 & 0.051 & 2.1 & 0.066 & 0.18 & 0.045 & 0.1 & 0.08 & 0.65 \\
\hline $\operatorname{area}\left(\mathrm{mm}^{2}\right)$ & 0.0324 & N/A & 0.5 & 0.03 & 0.08 & 0.04 & 0.021 & 0.09 & 0.04 \\
\hline Design Approach & cell-based & full-custom & full-custom & full-custom & full-custom & full-custom & full-custom & full-custom & cell-based \\
\hline
\end{tabular}

